\title{
Do Histamine-2 Receptor Antagonists and Proton Pump Inhibitors Really Have No Effect on the Gastric Emptying Rate?: Author's Reply
}

TO THE EDITOR: We appreciate sincerely the interest and comments of Dr. Tomita and Dr. Miwa ${ }^{1}$ on our paper on the "Effects of histamine-2 receptor antagonists and proton pump inhibitors on the rate of gastric emptying: a crossover study using a continuous real-time ${ }^{13} \mathrm{C}$ Breath Test (BreathID System)." ${ }^{2}$ As they pointed out, many studies have been conducted to exam the effects of gastric acid suppressants on gastric emptying, however, results from those studies have been controversial. Our study using liquid meals revealed that intravenous administration of gastric acid suppressants had no significant influence on the rate of gastric emptying. Indeed, the examination using solid meals might be more useful for the clinical setting. But in previous studies using solid meals, conflicting results were reported. ${ }^{3-5} \mathrm{We}$ speculate that various mechanisms induced by gastric acid suppressants, such as reduction of duodenal break, modification of volume and energy density of intragastric contents, delay in hydrolyzing and elevation of serum gastrin levels, might influence the rate of gastric emptying and interact respectively in a complicated manner.

We quite agree with Dr. Tomita and Dr. Miwa that more investigations regarding whether gastric acid suppressants enhance the gastric accommodation should be performed. This clinical implication is very interesting, because not only delayed gastric emptying but also defective gastric accommodation is considered as important pathogenesis of functional dyspepsia. Unfortunately, this hypothetical mechanisms induced by gastric acid suppressants, especially proton pump inhibitors, have never been investigated thoroughly. ${ }^{6}$ If gastric acid suppressants enhanced the gastric accommodation, the rate of gastric emptying would decelerate clearly. In our study, there were no significant differences in any of the parameters of gastric emptying measured with using the BreathID system among a single intravenous administration of famotidine, omeprazole and saline alone. Further investigation on the effects of gastric acid suppressants on the gastrointestinal motility should be conducted.

We again thank Dr. Tomita and Dr. Miwa for bringing some of their insightful thoughts on our paper.

Takashi Nonaka ${ }^{1}$ and Masahiko Inamori ${ }^{1,2}$ ${ }^{1}$ Gastroenterology Division and ${ }^{2}$ Office of Postgraduate Medical Education Yokohama City University Hospital, Yokohama, Japan

1. Tomita T, Miwa H. Do histamine-2 receptor antagonists and proton pump inhibitors really have no effect on the gastric emptying rate? J Neurogastroenterol Motil 2011;17:434.

2. Nonaka T, Kessoku T, Ogawa Y, et al. Effects of histamine-2 receptor antagonists and proton pump inhibitors on the rate of gastric emptying: a crossover study using a continuous real-time ${ }^{13} \mathrm{C}$ Breath Test (BreathID System)). J Neurogastroenterol Motil 2011;17:287293.

3. Parkman HP, Urbain JL, Knight LC, et al. Effect of gastric acid suppressants on human gastric motility. Gut 1998;42:243-250.

4. Horowitz M, Hetzel DJ, Buckle PJ, Chatterton BE, Shearman DJ. The effect of omeprazole on gastric emptying in patients with duodenal ulcer disease. Br J Clin Pharmacol 1984;18:791-794.

5. Chremos AN. Pharmacodynamics of famotidine in humans. Am J Med 1986;24:3-7.

6. Sanaka M, Yamamoto T, Kuyama Y. Effects of proton pump inhibitors on gastric emptying: a systematic review. Dig Dis Sci 2010; $55: 2431-2440$.

Conflicts of interest: None. 